\title{
10/10 HLA Match
}

National Cancer Institute

\section{Source}

National Cancer Institute. 10/10 HLA Match. NCI Thesaurus. Code C158471.

Complete HLA matching for HLA-A, -B, -C, -DRB1, and -DQB1 loci. 